\title{
Anti-stigma training for medical students: the Education Not Discrimination project
}

\author{
Bettina Friedrich, Sara Evans-Lacko, Jillian London, Danielle Rhydderch, Claire Henderson
} and Graham Thornicroft

\section{Background}

Education Not Discrimination (END) is the component of the Time to Change programme intended to reduce mental health stigma among professionals and professional trainees.

\begin{abstract}
Aims
To investigate the impact of the END anti-stigma programme on medical students immediately and after 6 months with regard to knowledge, attitudes, behaviour and empathy.
\end{abstract}

\section{Method}

A total of 1452 medical students participated in the study (intervention group $n=1066$, control group $n=386$ ).

Participants completed questionnaires at baseline, and at immediate and 6-month follow-up. Groups were compared for changes in stigma outcomes.

\section{Results}

All measures improved in both groups, particularly among students with less knowledge and more stigmatising attitudes and intended behaviour at baseline. At immediate follow-up the intervention group demonstrated significantly greater improvements in stigma-related knowledge and reductions in stigma-related attitudes and intended behaviour, relative to the control group. At 6 months' follow-up, however, only one attitude item remained significantly better.

\section{Conclusions}

Although the intervention produced short-term advantage there was little evidence for its persistent effect, suggesting a need for greater integration of ongoing measures to reduce stigma into the medical curriculum.

\section{Declaration of interest}

G.T. has received grants for stigma-related research in the past 5 years from Lundbeck UK and from the National Institute for Health Research, and has acted as a consultant to the UK Office of the Chief Scientist.
People with mental illness die prematurely. ${ }^{1-3}$ One reason is that their physical healthcare is on average worse than that provided to people without mental health problems. ${ }^{4}$ For example, people with mental illness have lower rates of coronary revascularisation, hospital admission for diabetes and basic assessments such as blood pressure measurement compared with people without a mental illness. ${ }^{5-8}$ There is a pressing need to improve understanding of the range of factors contributing to these inequalities. A potential mechanism underlying these disparities is discrimination against people with mental illness by health professionals who share the general public's stigmatising views towards such people. ${ }^{9,10}$ In keeping with these findings, the 2008 Stigma Shout survey of almost 4000 people using mental health services and carers conducted by the mental health charity Rethink Mental Illness identified medical professionals as one of the most important groups for Time to Change to target, ${ }^{11}$ and the Viewpoint survey showed that health professionals are a common source of experiences of discrimination reported by people with mental illness (see also Corker et al, this supplement). ${ }^{12,13}$ Rethink Mental Illness has a track record of anti-stigma work with medical and nursing students, ${ }^{14-16}$ and this work was continued as a component of the Time to Change programme (phase one: 2008-2011), called Education Not Discrimination (END). The aim of this study was to ascertain the effects of the training on medical students both immediately and after 6 months with respect to mental health-related knowledge, attitudes, intended behaviour and empathy. We predicted that there would be significantly greater improvement among intervention participants relative to control participants at immediate and 6-month follow-up for each of these outcomes.

\section{Method}

The END intervention for medical students was implemented between 2008 and 2011 at four medical schools in different regions of England. It was delivered as part of the medical training at the universities but participation was voluntary, as was participation in the study. The intervention had previously been delivered at one medical school and was based on previous work with police officers that combined educational and social contact elements. ${ }^{14,15,17-19}$ It consisted of a short lecture with key facts and figures about stigma and discrimination; testimonies about the experiences of mental health problems and stigma from people with direct experience of mental health problems, either personally or as carers; and role-plays in small groups, using professional role-players to act the parts of service users and carers. Medical students volunteered to role-play themselves in a medical history-taking scenario. Fellow students and actors then provided feedback after the role-play.

\section{Measures}

We used the following measures to assess mental health-related knowledge, attitudes, intended behaviour and empathy at three time points: baseline, immediate follow-up and 6-month follow-up.

\section{Knowledge}

Mental health-related knowledge was measured with the Mental Health Knowledge Schedule (MAKS). ${ }^{20}$ This comprised six items covering stigma-related mental health knowledge areas (help-seeking, recognition, support, employment, treatment and recovery) and six items that enquired about classification of various conditions as mental illnesses. ${ }^{21}$ Overall test-retest reliability of the MAKS was 0.71 and the overall internal consistency among items was $0.65 .^{20}$ The total score was calculated so that higher MAKS scores indicated greater knowledge. 


\section{Attitudes}

Mental health-related attitudes were measured using three items from the Community Attitudes toward the Mentally Ill (CAMI) scale: $^{22}$

(a) one of the main causes of mental illness is a lack of self-discipline and will-power;

(b) there is something about people with mental illness that makes it easy to tell them from normal people;

(c) it is frightening to think of people with mental problems living in residential neighbourhoods.

The choice of these particular items was made in cooperation with those facilitating and running the intervention so that they would specifically capture the defined attitude changes that were targeted by the intervention. On a five-point Likert scale participants were asked to indicate whether they agreed or disagreed with the three statements.

\section{Behaviour}

Behaviour was measured by the Reported and Intended Behaviour Scale (RIBS). ${ }^{23}$ We assessed changes in intended behaviour in four different contexts (living with, working with, living nearby and continuing a relationship with someone with a mental health problem) which were derived from the Star Social Distance Scale. ${ }^{24,25}$ Overall test-retest reliability of the RIBS was 0.75 and its overall internal consistency was 0.85 . The total intended behaviour score was calculated, with higher scores indicating more favourable intended behaviour.

\section{Empathy}

Four items from the Jefferson Scale of Physician Empathy were used. $^{26}$ These items tested awareness of the importance of the emotional status of the patients and their family; understanding the impact of emotional ties to their patient for healing; willingness to disclose mental health problems as linked to the fear of being treated differently; and feeling comfortable talking to a person with mental health problems. On a seven-point Likert scale the participants were asked to agree or disagree with empathyrelated statements. In a previous psychometric study the internal consistency reliability of the Jefferson empathy scale was found to be 0.89 for medical students. ${ }^{26}$

\section{Timing of assessments}

Immediately before the first part of the intervention (lecture and testimonies) participants completed the baseline questionnaire including all four stigma measures in addition to sociodemographic details (date of birth, gender and ethnic origin). Participants completed the first follow-up immediately after the second and last part of the intervention (the role-play). Six months later participants were asked by email to complete the online followup questionnaire, a link to which was provided in the email. Participants in the control group did not receive any of the END intervention and received their standard medical school curriculum.

\section{Participants}

The study inclusion criteria were being a third-year medical student enrolled at one of the four participating medical schools, providing a valid email address for the online follow-up and giving valid written consent. Potential participants were contacted by their schools in advance about the intervention and the planned study before being recruited to the study at the sites where they received teaching. The lecture and the testimony that comprised the END intervention were scheduled in the educational plan for the students but the intervention did not constitute obligatory modules of their training. Researchers (either from the Institute of Psychiatry or the Mental Health Research Network) collected data from study participants who attended the initial part of the intervention (lecture and testimony). Before the start of the lecture, an information sheet, consent form and baseline questionnaire were distributed to the participants and collected immediately after completion. Approval was obtained from the King's College London research ethics committee.

Control participants were recruited from two sites. At one university, students were randomised by the academic registry to either intervention or control group. At another, two out of six student groups based at different sites were recruited to the control group.

\section{Statistical analysis}

We calculated total scores for the MAKS, RIBS and empathy scales by adding the respective items so that a higher total score would represent less stigmatising responses. The CAMI scores were not added but were analysed at item level. Score changes were measured at two time comparison points: the change between baseline and immediate follow-up, and the change between baseline and 6-month follow-up. Separate linear regression models were used to investigate changes in knowledge, attitude, intended behaviour and empathy outcomes at both follow-up points. Covariates used in the regression model included group membership (control $v$. intervention), age (continuous), gender (male $v$. female), ethnicity (Black and minority ethnic $v$. others) and the respective baseline scores. We calculated the adjusted and unadjusted values (i.e. univariate and multivariate regressions).

\section{Results}

Table 1 describes the demographic characteristics of the participants. Most participants were aged 25 years or younger (mean 23.5 years), White and female. Chi-squared tests were calculated to establish whether there were any demographic differences between the intervention group and the control group. Compared with the intervention group, the control group had more people in the lower age categories: $\chi^{2}(4, n=1433)=10.1$, $P=0.04$. With this exception, the demographic profiles of the control and intervention groups were similar. Chi-squared tests were also calculated to investigate whether there was systematic drop-out between baseline and follow-up for control $v$. intervention group. Only one of the chi squared tests was significant: Black and minority ethnic (BME) participants were more likely than White participants to take part in the immediate follow-up: $\chi^{2}(1, n=1443)=4.1, \quad P=0.05$. There was no other difference in drop-out rates for the immediate follow-up or the 6-month follow-up in terms of the demographic variables collected.

\section{Knowledge}

Compared with those in the control group, those in the intervention group had significantly greater improvements in mental health-related knowledge at immediate follow-up. Immediate improvement in knowledge was also associated with lower baseline score and non-BME ethnicity. Those in the intervention group did not show greater improvements in knowledge at the 


\begin{tabular}{|c|c|c|c|c|c|c|}
\hline & \multicolumn{2}{|c|}{ Baseline $(n=1452)$} & \multicolumn{2}{|c|}{ Immediate follow-up $(n=625)$} & \multicolumn{2}{|c|}{ 6-month follow-up $(n=137)$} \\
\hline & Intervention & Control & Intervention & Control & Intervention & Control \\
\hline \multicolumn{7}{|l|}{ Age, years: $n$ (\%) } \\
\hline$\leqslant 25$ & $858(80)$ & $335(87)$ & $310(81)$ & $207(86)$ & $75(75)$ & $30(81)$ \\
\hline $26-35$ & $167(16)$ & $43(11)$ & $67(17)$ & $31(13)$ & $25(25)$ & $7(19)$ \\
\hline $36-45$ & $23(2)$ & $4(1)$ & $5(1)$ & $2(1)$ & $0(0)$ & $0(0)$ \\
\hline $46-55$ & $1(0)$ & $2(1)$ & $0(0)$ & $1(0)$ & $0(0)$ & $0(0)$ \\
\hline Missing & $17(2)$ & $2(1)$ & $2(1)$ & $0(0)$ & $0(0)$ & $0(0)$ \\
\hline Age, years: mean & 23.6 & 23.3 & 23.5 & 23.3 & 23.6 & 23.4 \\
\hline \multicolumn{7}{|l|}{ Ethnicity, $n(\%)$} \\
\hline White & $661(62)$ & $260(67)$ & $233(61)$ & $147(61)$ & $65(65)$ & $28(76)$ \\
\hline Mixed & $38(4)$ & $17(4)$ & $11(3)$ & $10(4)$ & $2(2)$ & $3(8)$ \\
\hline Asian or Asian British & 247 (23) & $72(19)$ & $105(27)$ & $58(24)$ & $23(23)$ & $6(16)$ \\
\hline Black or Black British & $35(3)$ & $14(4)$ & $6(2)$ & $12(5)$ & $2(2)$ & $0(0)$ \\
\hline Chinese or other ethnic group & $80(8)$ & $19(5)$ & $29(8)$ & $13(5)$ & $8(8)$ & $0(0)$ \\
\hline Missing & $5(0)$ & $4(1)$ & $0(0)$ & $1(0)$ & $0(0)$ & $0(0)$ \\
\hline \multicolumn{7}{|l|}{ Gender, $n$ (\%) } \\
\hline Male & $383(36)$ & $133(35)$ & 127 (33) & $84(35)$ & $33(33)$ & $11(30)$ \\
\hline Female & $587(55)$ & $216(56)$ & $226(59)$ & $131(54)$ & $61(61)$ & $24(65)$ \\
\hline Missing & $96(9)$ & $37(10)$ & $31(8)$ & $26(11)$ & $6(6)$ & $2(5)$ \\
\hline Total, $n(\%)$ & $1066(100)$ & $386(100)$ & $384(100)$ & $241(100)$ & $100(100)$ & $37(100)$ \\
\hline
\end{tabular}

6-month follow-up compared with controls. The baseline MAKS score, however, predicted the improvement, with individuals with a lower baseline MAKS score showing greater improvements (Table 2).

\section{Attitude}

Compared with the control group, those in the intervention group had significantly greater improvements in mental health-related attitudes at immediate follow-up for two of the three CAMI items ('There is something about people with mental illness that makes it easy to tell them from normal people' and 'It is frightening to think of people with mental problems living in residential neighbourhoods'). Furthermore, the baseline score predicted the short-term changes for all attitude items, with the greatest improvements occurring in the people with lower baseline scores. At 6 months' follow-up attitudinal improvement was significantly better among those in the intervention group for the second attitude item only ('There is something about people with mental illness that makes it easy to tell them from normal people'). For all three CAMI items, White ethnicity and lower baseline CAMI score were also significant predictors of greater improvement (Table 3). Older age was associated with significantly greater improvement in the first attitude item ('One of the main causes of mental illness is a lack of self-discipline and will-power').

\section{Intended behaviour}

Participants in the intervention group had a significantly greater improvement in intended behaviour at immediate follow-up relative to participants in the control group. Additionally, those with a lower baseline RIBS score and White participants (compared with the BME group) had a significantly greater CAMI score at immediate follow-up. Intervention and control participants did not have significantly different long-term changes at 6-month follow-up. Only lower baseline RIBS score was associated with greater improvements in RIBS score at 6-month follow-up (Table 4).

\section{Empathy}

Empathy increased significantly more in people who participated in the intervention at immediate follow-up. Furthermore, lower baseline empathy score was associated with greater changes in empathy at immediate follow-up. At the 6-month follow-up, however, only lower baseline empathy score was associated with a greater improvement in empathy (Table 5).

\section{Discussion}

The results show significantly greater improvements at immediate follow-up for all stigma-related outcomes - mental health-related knowledge, attitudes, intended behaviour and empathy - among

Table 2 Predictors of mental health-related knowledge improvements at follow-up (linear regression)

\begin{tabular}{|c|c|c|c|c|c|c|c|c|}
\hline & \multicolumn{4}{|c|}{ Immediate follow-up } & \multicolumn{4}{|c|}{ 6-month follow-up } \\
\hline & \multicolumn{2}{|c|}{$\begin{array}{l}\text { Univariate regression } \\
\text { (unadjusted) }\end{array}$} & \multicolumn{2}{|c|}{$\begin{array}{l}\text { Multivariable regression } \\
\text { (adjusted) }\end{array}$} & \multicolumn{2}{|c|}{$\begin{array}{l}\text { Univariate regression } \\
\text { (unadjusted) }\end{array}$} & \multicolumn{2}{|c|}{$\begin{array}{l}\text { Multivariable regression } \\
\text { (adjusted) }\end{array}$} \\
\hline & Standardised $\beta$ & $P$ & Standardised $\beta$ & $P$ & Standardised $\beta$ & $P$ & Standardised $\beta$ & $P$ \\
\hline Intervention $v$. control & $<0.01$ & 0.95 & $0.11 *$ & $<0.01$ & -0.03 & 0.56 & 0.00 & 0.98 \\
\hline Baseline score & $-0.60^{\star}$ & $<0.01$ & $-0.66^{\star}$ & $<0.01$ & $-0.60 *$ & $<0.01$ & $-0.60 *$ & $<0.01$ \\
\hline Ethnicity (White $v$. BME) & 0.02 & 0.71 & $0.10^{*}$ & $<0.01$ & 0.03 & 0.59 & 0.08 & 0.11 \\
\hline Gender (female $v$. male) & -0.02 & 0.56 & 0.02 & 0.51 & -0.03 & 0.67 & 0.04 & 0.45 \\
\hline Age (continuous) & 0.02 & 0.70 & 0.03 & 0.32 & 0.04 & 0.53 & 0.01 & 0.90 \\
\hline
\end{tabular}


Table 3 Predictors of mental health-related attitude improvements at follow-up (linear regression)

\begin{tabular}{|c|c|c|c|c|c|c|c|c|}
\hline \multirow[b]{3}{*}{ CAMI item } & \multicolumn{4}{|c|}{ Immediate follow-up } & \multicolumn{4}{|c|}{ 6-month follow-up } \\
\hline & \multicolumn{2}{|c|}{$\begin{array}{l}\text { Univariate regression } \\
\quad \text { (unadjusted) }\end{array}$} & \multicolumn{2}{|c|}{$\begin{array}{l}\text { Multivariable regression } \\
\text { (adjusted) }\end{array}$} & \multicolumn{2}{|c|}{$\begin{array}{l}\text { Univariate regression } \\
\text { (unadjusted) }\end{array}$} & \multicolumn{2}{|c|}{$\begin{array}{l}\text { Multivariable regression } \\
\text { (adjusted) }\end{array}$} \\
\hline & Standardised $\beta$ & $P$ & Standardised $\beta$ & $P$ & Standardised $\beta$ & $P$ & Standardised $\beta$ & $P$ \\
\hline \multicolumn{9}{|c|}{ One of the main causes of mental illness is a lack of self-discipline and will-power } \\
\hline Intervention $v$. control & 0.05 & 0.25 & 0.06 & 0.08 & 0.02 & 0.75 & 0.01 & 0.82 \\
\hline Baseline score & $-0.64^{\star}$ & $<0.01$ & $-0.68^{*}$ & 0.00 & $-0.66^{\star}$ & $<0.01$ & $-0.66^{*}$ & $<0.01$ \\
\hline Ethnicity (White $v$. BME) & -0.08 & 0.07 & 0.07 & 0.06 & 0.03 & 0.62 & $0.11^{*}$ & 0.02 \\
\hline Gender (female $v$. male) & -0.01 & 0.91 & 0.06 & 0.08 & -0.03 & 0.67 & 0.04 & 0.46 \\
\hline Age (continuous) & -0.01 & 0.77 & -0.05 & 0.18 & 0.06 & 0.31 & $0.11 *$ & 0.02 \\
\hline \multicolumn{9}{|c|}{ There is something about people with mental illness that makes it easy to tell them from normal people } \\
\hline Intervention $v$. control & $0.10^{*}$ & 0.02 & $0.87^{*}$ & 0.02 & 0.11 & 0.06 & $0.12^{*}$ & 0.01 \\
\hline Baseline score & $-0.55^{\star}$ & $<0.01$ & $0.57^{*}$ & 0.00 & $-0.61 *$ & $<0.01$ & $-0.61 *$ & $<0.01$ \\
\hline Ethnicity (White $v$. BME) & -0.07 & 0.10 & 0.02 & 0.59 & 0.10 & 0.10 & $0.12^{*}$ & 0.02 \\
\hline Gender (female $v$. male) & -0.01 & 0.74 & 0.07 & 0.07 & -0.10 & 0.12 & -0.02 & 0.67 \\
\hline Age (continuous) & 0.02 & 0.60 & 0.03 & 0.42 & 0.02 & 0.80 & 0.06 & 0.27 \\
\hline \multicolumn{9}{|c|}{ It is frightening to think of people with mental problems living in residential neighbourhoods } \\
\hline Intervention $v$. control & $0.10^{*}$ & 0.01 & $0.11^{*}$ & $<0.01$ & -0.04 & 0.56 & 0.03 & 0.59 \\
\hline Baseline score & $-0.62^{*}$ & 0.00 & $-0.65^{\star}$ & $<0.01$ & $-0.60^{\star}$ & $<0.01$ & $-0.65^{\star}$ & $<0.01$ \\
\hline Ethnicity (White $v$. BME) & -0.05 & 0.24 & 0.09 & 0.12 & -0.01 & 0.91 & $0.11 *$ & 0.03 \\
\hline Gender (female $v$. male) & -0.01 & 0.83 & -0.09 & 0.78 & 0.04 & 0.53 & -0.03 & 0.60 \\
\hline Age (continuous) & 0.03 & 0.48 & 0.04 & 0.31 & -0.03 & 0.62 & 0.03 & 0.60 \\
\hline
\end{tabular}

Table 4 Predictors of mental health-related intended behaviour at follow-up (linear regression)

\begin{tabular}{|c|c|c|c|c|c|c|c|c|}
\hline \multirow[b]{3}{*}{ CAMI item } & \multicolumn{4}{|c|}{ Immediate follow-up } & \multicolumn{4}{|c|}{ 6-month follow-up } \\
\hline & \multicolumn{2}{|c|}{$\begin{array}{l}\text { Univariate regression } \\
\quad \text { (unadjusted) }\end{array}$} & \multicolumn{2}{|c|}{$\begin{array}{l}\text { Multivariable regression } \\
\text { (adjusted) }\end{array}$} & \multicolumn{2}{|c|}{$\begin{array}{l}\text { Univariate regression } \\
\text { (unadjusted) }\end{array}$} & \multicolumn{2}{|c|}{$\begin{array}{l}\text { Multivariable regression } \\
\text { (adjusted) }\end{array}$} \\
\hline & Standardised $\beta$ & $P$ & Standardised $\beta$ & $P$ & Standardised $\beta$ & $P$ & Standardised $\beta$ & $P$ \\
\hline Intervention v. control & $0.10^{*}$ & 0.02 & $0.13^{*}$ & $<0.01$ & -0.03 & 0.63 & -0.01 & 0.92 \\
\hline Baseline score & $-0.57^{*}$ & $<0.01$ & $-0.59^{*}$ & $<0.01$ & $-0.57^{*}$ & $<0.01$ & $-0.56^{*}$ & $<0.01$ \\
\hline Ethnicity (White $v$. BME) & -0.08 & 0.06 & $0.09 *$ & 0.02 & -0.04 & 0.51 & 0.05 & 0.33 \\
\hline Gender (female $v$. male) & -0.65 & 0.52 & 0.00 & 0.99 & -0.12 & 0.06 & -0.05 & 0.31 \\
\hline Age (continuous) & -0.04 & 0.38 & -0.06 & 0.12 & -0.12 & 0.50 & -0.08 & 0.11 \\
\hline
\end{tabular}

\begin{tabular}{|c|c|c|c|c|c|c|c|c|}
\hline \multirow[b]{3}{*}{ CAMI item } & \multicolumn{4}{|c|}{ Immediate follow-up } & \multicolumn{4}{|c|}{ 6-month follow-up } \\
\hline & \multicolumn{2}{|c|}{$\begin{array}{l}\text { Univariate regression } \\
\quad \text { (unadjusted) }\end{array}$} & \multicolumn{2}{|c|}{$\begin{array}{l}\text { Multivariable regression } \\
\text { (adjusted) }\end{array}$} & \multicolumn{2}{|c|}{$\begin{array}{l}\text { Univariate regression } \\
\text { (unadjusted) }\end{array}$} & \multicolumn{2}{|c|}{$\begin{array}{l}\text { Multivariable regression } \\
\text { (adjusted) }\end{array}$} \\
\hline & Standardised $\beta$ & $P$ & Standardised $\beta$ & $P$ & Standardised $\beta$ & $P$ & Standardised $\beta$ & $P$ \\
\hline Intervention $v$. control & 0.06 & 0.13 & $0.07 *$ & 0.04 & -0.06 & 0.36 & -0.02 & 0.68 \\
\hline Baseline score & $-0.57^{\star}$ & $<0.01$ & $-0.58^{*}$ & $<0.01$ & $-0.55^{\star}$ & $<0.01$ & $-0.55^{\star}$ & $<0.01$ \\
\hline Ethnicity (White $v$. BME) & -0.04 & 0.33 & 0.03 & 0.40 & -0.02 & 0.80 & $<0.01$ & 0.99 \\
\hline Gender (female $v$. male) & -0.05 & 0.28 & $<0.01$ & 0.94 & -0.01 & 0.85 & 0.46 & 0.39 \\
\hline Age (continuous) & 0.04 & 0.29 & 0.05 & 0.13 & 0.06 & 0.35 & 0.08 & 0.12 \\
\hline
\end{tabular}

medical students receiving the Time to Change END intervention relative to those in the control group. However, this advantage did not persist. Six months following the intervention only one attitude item was associated with a greater improvement in the intervention group relative to the control group. This is a matter of concern which requires consideration.

One explanation for the short-term nature of its impact is that the intervention coincided with the start of the psychiatric rotation for both groups, the impact of which may have nullified any effect on the outcomes of the END training. Evaluation of previous similar interventions with medical students also showed that it was effective in improving knowledge at 1 week, ${ }^{15}$ whereas police officers reported that the intervention they received helped them improve their communication with people with mental health problems and increased their confidence to support people in mental distress. ${ }^{18}$ However, the intervention with the police had no impact on the extent of their endorsement of the stereotype of people with mental illness as 
violent, suggesting that professional experience also has an influence on attitudes.

A second possible explanation for the decrease in difference at 6 months is that people in the control group might have been influenced by priming after having been prompted to answer questions on their mental health-related knowledge, attitudes, intended behaviour and empathy at baseline, resulting possibly in a short-term positive attitude shift which was diminished at the long-term follow up. Future studies might consider a Solomon group design to control for such effects. ${ }^{27}$ Third, one might also consider the possibility that the training might have had a longer-lasting effect if it had been more specifically targeted towards medical students. In a qualitative assessment, medical students reported feeling somewhat patronised by the lecture's content because they felt that the factual knowledge and training on mental health problems received at their respective medical schools made this part of the intervention unnecessary. However, they felt more positive about the testimonies of people using mental health services, in that learning about the patient's perspective affected the students' attitudes and provided an insight into mental health topics that their formal education had not provided (details available from the author on request). Sadow \& Ryder also found that a personal presentation from someone with experience of mental health treatment made a greater impact on attitudes of future health professionals than purely educational interventions. ${ }^{28}$ Fourth, external events such as influential news events or media stories (e.g. a reported shooting rampage by somebody who is described as having mental health problems) might have affected mental health-related stigma, potentially explaining similar changes in the intervention and control group as having influenced both groups alike. In this study, however, the observation periods for the different groups were staggered, being determined by the start of the respective psychiatric rotations for the different cohorts over 3 years.

On a more positive note, lower baseline scores were consistent predictors of greater improvements in knowledge, attitudes, intended behaviour and empathy at immediate follow-up and 6 months later. These findings suggest that those with more stigmatising attitudes towards mental health benefit most from the intervention. This is similar to a finding from Galletly \& Burton, who showed that students with the most negative attitudes towards people with schizophrenia benefited most from an anti-stigma intervention and displayed the greatest improvement in attitudes. ${ }^{29}$ Similar findings were demonstrated by the qualitative assessment of the END training, which suggested that the impact of the training depended on the knowledge, attitude, behaviour and empathy that the participants showed before participating in the training (details available from the author on request). This underlines the importance of identifying and targeting groups with a higher need for mental health-related education. At 6-month follow-up participants' attitudes in the BME group improved more than attitudes in the White group. These findings correspond to research reported by Knifton et al, who showed that there is a variety of need in mental health education between different ethnic groups, which might influence the efficacy of anti-stigma training. ${ }^{30}$

\section{Limitations}

Control groups were only available at two of the four participating medical schools, so our control group may have differed from the intervention group in terms of variables other than the measured demographic characteristics we controlled for. Second, for feasibility the questionnaire had to be short, thus only three items from the CAMI were included instead of either the original scale or the shortened version used in the Attitudes to Mental Illness survey. ${ }^{31}$ Further, as Bargh et al showed, ${ }^{32}$ attitudes are not always explicitly and consciously accessible and changeable, and this applies to mental health stigma. Last, we are unable to provide evidence on whether those who received the intervention would behave differently towards people with mental health problems in their clinical practice. Mechanisms and processes of stigma and discrimination have to be better understood to improve the efficacy of anti-stigma interventions. ${ }^{33}$

\section{Implications}

Future research needs to investigate how it can be assured that positive changes prevail over time. First, although there is good evidence that interventions in the form of personal testimonies can be effective, ${ }^{16,18,34}$ it may be that different types of intervention content have differential effectiveness, in line with what has been found for public education campaigns. ${ }^{35}$ In this case research is required to establish what the most effective ingredients are. Second, it may be that 'booster' sessions are needed to maintain gains over time and this should be investigated further. A third possibility is greater integration between anti-stigma training and the rest of medical student education. If medical students learn negative attitudes and behaviour towards people with mental health problems from their role models, this will render training such as END ineffectual beyond its immediate impact. This potential problem is significant in the context of professional training based on the apprenticeship model; on the other hand, if doctors show leadership by tackling stigma and modelling non-discriminatory practice then the impact of training such as END could be better sustained.

\section{Bettina Friedrich, PhD, Sara Evans-Lacko, PhD, Jillian London, MSC, Danielle} Rhydderch, MA(Cantab), Claire Henderson, PhD, Graham Thornicroft, PhD,

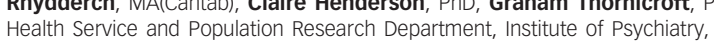
London, UK

Correspondence: Dr Claire Henderson, Health Service and Population Research Department, Box PO29, Institute of Psychiatry, De Crespigny Park, London SE5 8AF, UK. Email: Claire.1.Henderson@kcl.ac.uk

\section{Funding}

The study was part funded by the Big Lottery Fund, Comic Relief and Shifting Attitudes to Mental IIIness (SHIFT), UK government Department of Health, through their funding of the Time to Change programme. G.T. and C.H. are funded in relation to a National Institute for Health Research (NIHR) Applied Programme grant awarded to the South London and Maudsley NHS Foundation Trust (G.T.). D.R. and G.T. are also supported in relation to the NIHR Specialist Mental Health Biomedical Research Centre at the Institute of Psychiatry, King's College London and the South London and Maudsley NHS Foundation Trust (G.T.). C.H. is also funded by a grant from Guy's and St Thomas' Charity.

\section{Acknowledgements}

We thank the Education Not Discrimination team from Rethink Mental Illness for facilitating the data collection at interventions, and Sue Baker, Maggie Gibbons and Paul Farmer (Mind) and Paul Corry and Mark Davies (Rethink Mental Illness) for their collaboration. Further, we thank the Mental Health Research Network and other helpers for their invaluable support in collecting the data. We are also pleased to thank Paul Willams for advice regarding the databases and statistical analysis.

\section{References}

1 Harris EC, Barraclough B. Excess mortality of mental disorder. Br J Psychiatry 1998; 173: 11-53.

2 Thornicroft G. Physical health disparities and mental illness: the scandal of premature mortality. Br J Psychiatry 2011; 199: 441-2.

3 Wahlbeck K, Westman J, Nordentoft M, Gissler M, Laursen TM. Outcomes of Nordic mental health systems: life expectancy of patients with mental disorders. Br J Psychiatry 2011; 199: 453-8. 
4 Disability Rights Commission. Equal Treatment: Closing the Gap. A Formal Investigation into Physical Health Inequalities Experienced by People with Learning Disabilities and/or Mental Health Problems. Disability Rights Commission, 2006

5 Druss BG, Bradford DW, Rosenheck RA, Radford MJ, Krumholz HM. Mental disorders and use of cardiovascular procedures after myocardial infarction. JAMA 2000; 283: 506-11.

6 Lawrence DM, Holman CD, Jablensky AV, Hobbs M.S. Death rate from ischaemic heart disease in Western Australian psychiatric patients 1980-1988. Br J Psychiatry 2003; 182: 31-6.

7 Sullivan G, Han X, Moore S, Kotrla K. Disparities in hospitalization for diabetes among persons with and without co-occurring mental disorders. Psychiatr Serv 2006; 57: 1126-31.

8 Roberts L, Roalfe A, Wilson S, Lester H. Physical health care of patients with schizophrenia in primary care: a comparative study. Fam Pract 2007 : 24: 34-40.

9 Lauber C, Anthony M, Jdacic-Gross V, Rossler W. What about psychiatrists' attitude to mentally ill people? Eur Psychiatry 2004; 19: 423-7.

10 Patel MX. Attitudes to psychosis: health professionals. Epidemiol Psichiatr Soc 2004; 13: 213-8.

11 Time to Change. Stigma Shout Survey (http://www.time-to-change.org.uk/ news/stigma-shout-survey-shows-real-impact-stigma-and-discrimination-peoples-lives).

12 Henderson C, Corker E, Lewis-Holmes E, Hamilton S, Flach C, Rose D, et al. Reducing mental health related stigma and discrimination in England: one year outcomes of the Time to Change Programme for service user-rated experiences of discrimination. Psychiatr Serv 2012; 63: 451-7.

13 Corker E, Hamilton S, Henderson C, Weeks C, Pinfold V, Rose D, et al. Experiences of discrimination among people using mental health services in England 2008-2011. Br J Psychiatry 2013; 202 (suppl 55): s58-63.

14 Kassam A, Glozier N, Leese M, Henderson C, Thornicroft G. Development and responsiveness of a scale to measure clinicians' attitudes to people with mental illness (medical student version). Acta Psychiatr Scand 2010; 122 153-61.

15 Kassam A, Glozier N, Leese M, Loughran J, Thornicroft G. A controlled trial of mental illness related stigma training for medical students. BMC Med Educ 2011; 11: 51.

16 Clement S, van Nieuwenhuizen A, Kassam A, Flach C, Lazarus A, de Castro $M$, et al. Filmed $v$. live social contact interventions to reduce stigma: randomised controlled trial. Br J Psychiatry 2011; 201: 57-64.

17 Pinfold V, Huxley P, Thornicroft G, Farmer P, Toulmin H, Graham T. Reducing psychiatric stigma and discrimination - evaluating an educational intervention with the police force in England. Soc Psychiatry Psychiatr Epidemiol 2003; 38: 337-44.

18 Pinfold V, Thornicroft G, Huxley P, Farmer P. Active ingredients in anti-stigma programmes in mental health. Int Rev Psychiatry 2005; 17: 123-31.
19 Thornicroft G, Rose D, Kassam A. Discrimination in health care against people with mental illness. Int Rev Psychiatry 2007; 19: 113-22.

20 Evans-Lacko S, Little K, Meltzer H, Rose D, Rhydderch D, Henderson C, et al. Development and psychometric properties of the Mental Health Knowledge Schedule. Can J Psychiatry 2010; 55: 440-8.

21 Rusch N, Evans-Lacko $S$, Thornicroft $G$. What is a mental illness? Public views and their effects on attitudes and disclosure. Aust N Z J Psychiatry 2012; 46: 641-50.

22 Taylor SM, Dear MJ. Scaling community attitudes toward the mentally ill. Schizophr Bull 1981; 7: 225-40

23 Evans-Lacko S, Rose D, Little K, Flach C, Rhydderch D, Henderson C, et al. Development and psychometric properties of the reported and intended behaviour scale (RIBS): a stigma-related behaviour measure. Epidemiol Psychiatr Sci 2011; 20: 263-71.

24 Phillips D. Identification of mental illness: its consequences for rejection. Community Ment Health J 1967; 3: 262-6.

25 Link BG, Yang LH, Phelan JC, Collins PY. Measuring mental illness stigma. Schizophr Bull 2004; 30: 511-41.

26 Hojat M, Gonnella JS, Nasca TJ, Mangione S, Veloksi JJ, Magee M. The Jefferson Scale of Physician Empathy: further psychometric data and differences by gender and specialty at item level. Acad Med 2002; 77 (suppl): S58-60.

27 Solomon RL. An extension of control group design. Psychol Bull 1949; 46: 137.

28 Sadow D, Ryder M. Reducing stigmatizing attitudes held by future health professionals: the person is the message. Psychol Serv 2008; 5: 362.

29 Galletly C, Burton C. Improving medical student attitudes towards people with schizophrenia. Aust N Z J Psychiatry 2011; 45: 473-6.

30 Knifton L, Gervais M, Newbigging K, Mirza N, Quinn N, Wilson N, et al. Community conversation: addressing mental health stigma with ethnic minority communities. Soc Psychiatry Psychiatr Epidemiol 2010; 45: 497-504.

31 Mehta N, Kassam A, Leese M, Butler G, Thornicroft G. Public attitudes towards people with mental illness in England and Scotland, 1994-2003. Br J Psychiatry 2009; 194: 278-84.

32 Bargh JA, Chaiken S, Govender R, Pratto F. The generality of the automatic attitude activation effect. J Pers Soc Psychol 1992; 62: 893-912.

33 Hinshaw SP, Stier A. Stigma as related to mental disorders. Annu Rev Clin Psychol 2008; 4: 367-93.

34 Corrigan PW, River LP, Lundin RK, Penn DL, Uphoff-Wasowski K, Campion J, et al. Three strategies for changing attributions about severe mental illness. Schizophr Bull 2001; 27: 187-95.

35 Clement $\mathrm{S}$, Jarrett $\mathrm{M}$, Henderson $\mathrm{C}$, Thornicroft G. Messages to use in population-level campaigns to reduce mental health-related stigma: consensus development study. Epidemiol Psichiatr Soc 2010; 19: 72-9. 